4 National Occupational Health and Safety Commission. Workrelated traumatic fatalities in Australia, 1989 to 1992. Sydney: NOHSC, 1998.

5 National Occupational Health and Safety Commission. Workrelated traumatic fatalities in New South Wales, 1989 to 1992. Sydney: NOHSC, 1999.

6 Harrison J, Frommer M, Ruck E, Blyth F. Deaths as a result of work-related injury in Australia. Med J Aust 1989; 150: $118-125$.
7 WorkCover NSW. Statistical Bulletin 1998-99, NSW workers' compensation. Sydney: WorkCover NSW, 2000.

8 Workplace Relations Ministers' Council. Comparative performance monitoring. Third report. Australian \& New Zealand OHS and workers' compensation schemes. Canberra: Department of Employment, Workplace Relations and Small Business, 2001.

\title{
FARM-RELATED INJURY IN NSW: INFORMATION FOR PREVENTION
}

\section{Richard Franklin and Justin Crosby \\ Australian Centre for Agricultural Health and Safety \\ University of Sydney, Moree}

Over the past decade, information about injuries on farms has grown; however, due to the time-consuming and costly nature of its capture, detailed analysis of events of injury has been limited. The aggregation of information has also proven difficult due to various coding frameworks and definitions being used. This article describes some of the information that can assist in the prevention of farmrelated injury in NSW.

\section{THE FARM INJURY OPTIMAL DATASET}

In 1994, the Australian Centre for Agricultural Health and Safety started to develop an optimal dataset for use in the collection of information describing agricultural injury. ${ }^{1}$ This dataset was made available for use in late 1996. In 1999 the dataset was updated, after it had been used for various studies and some of the practical problems associated with its application had been resolved. ${ }^{2}$ The production of an optimal dataset for farm injury has allowed both the aggregation of data from studies from different areas and over different time frames and the subsequent comparison of these studies.

In 1995, the National Occupational Health and Safety Commission undertook the largest collection of data describing work-related fatalities in Australia covering the period 1989-1992. ${ }^{3}$ As part of this study, the Farm Injury Optimal Dataset was used to code farm-related deaths. The Australian Centre for Agricultural Health and Safety and the National Occupational Health and Safety Commission produced a detailed report on farm-related fatalities. $^{4}$

\section{FARM-RELATED FATALITIES IN NSW}

The investigation of farm-related fatalities in NSW during the period 1989-1992, which was undertaken as part of the national study, found that there were 185 unintentional deaths on or related to farms. At the time of their fatal injury, 124 people (67.0 per cent) were working, 34 (18.4 per cent) were bystanders to the incident (a person who was injured as a result of workplace activities or by a piece of equipment which was present on the farm to perform work functions), and 27 (14.6 per cent) were involved in other farm incidents (injuries that were not a result of work or work-related). ${ }^{4}$

On average, there were 46 farm-related fatalities on NSW farms per annum, or 39 work-related farm fatalities on NSW farms per annum. There were 193 people who were fatally injured on NSW farms (both intentionally and unintentionally); this gave a rate of 1.09 fatalities per 10,000 agricultural establishments in NSW. ${ }^{4}$

Rates and numbers are all very well when you are examining an issue over time or determining the size of a problem, or if you are examining the effect that a program has had in reducing the problem. Rates and numbers are less able to determine where you should be directing your prevention activities, what these activities should be, or where you should spend resources gathering greater detail about the event of injury. ${ }^{4}$

The study by Franklin et al. (2000) examined the farmrelated deaths in NSW in detail including information about gender, age, farm enterprise, location on farm, agent, mechanism, activity at time of injury, pathophysiological cause of death, blood-alcohol content, month, day, and status of visitor to the farm. ${ }^{4}$ 
Examining the overall results of the study for NSW, it was found that the most common types of farm enterprises where the fatal incident occurred were producing:

- cereal grains, sheep, cattle, and pigs;

- cattle for meat;

- sheep for meat and wool.

The most common locations of the fatal incident were roads and lanes, paddocks cleared for grazing, and paddocks under crop. For working fatalities, tractors, aircraft, and trucks were common agents involved in the incident. Dams and tractors were common agents of the fatal incident for bystanders. ${ }^{4}$

The common mechanisms of the fatal incident for workers were vehicle accidents, being hit by moving objects (most commonly tractors), being hit by falling objects (mainly trees being felled), and rollovers of mobile machinery (mainly tractors). Common mechanisms of the fatal incident for bystanders were drowning and being hit by moving objects. The most common activities undertaken by workers at the time of the fatal incident were transport for work purposes, maintenance activities, and working with crops. Bystanders were commonly involved in recreation or playing activities. ${ }^{4}$

\section{HOSPITAL ADMISSION FROM FARM INJURIES}

Information collected when there is a fatality on a farm provides substantial information about the event of injury, but fatalities only represent about 10 per cent of all injuries sustained on farms. Injuries resulting in hospitalisation often represent injuries that are more severe than injuries that are presented to the surgeries of general practitioners. In NSW, there are over 1000 hospitalisations for injury per annum, where the location is a farm. Farmsafe Australia has selected a group of $\mathrm{E}$ codes to describe key injuries occurring on farms (Table 1$){ }^{5}$

Causes of farm-related injury, where there are a large number of injuries requiring hospitalisation include injuries from:

- riding animals;

- riding motorcycles, but often involving animals;

- riding agricultural vehicles;

- using agricultural machinery, which result in cutting and piercing. ${ }^{5}$

Does information from hospital admissions help with prevention efforts? Unlike information from coronial records, information recorded by a hospital has few details describing the circumstances surrounding the event of injury. There is, however, a large number of hospital admissions; for NSW we can see from Table 1 that over seven fiscal years there has been no reduction in the number of injuries to individuals who have been hospitalised as a result of farm-related injury. This information is useful at a local level and can be analysed by gender and age groups. The information on farm-related

\section{TABLE 1}

HOSPITAL SEPARATIONS FOR FARM INJURY, ALL AGES, NSW, 1989-90 TO 1995-96 5

\begin{tabular}{|c|c|c|c|c|c|c|c|c|}
\hline \multirow{2}{*}{$\begin{array}{l}\text { E-Code } \\
\text { E820-E829 }\end{array}$} & \multirow{2}{*}{$\begin{array}{l}\text { Description } \\
\text { Motor vehicle non traffic accidents \& } \\
\text { other road vehicle accidents }\end{array}$} & \multicolumn{7}{|c|}{$\begin{array}{l}\text { NSW hospital separations all ages } \\
1989-90 \text { 1990-91 1991-92 1992-93 1993-94 1994-95 1995-96 }\end{array}$} \\
\hline & & & & & & & & \\
\hline & Motor cycle & 205 & 206 & 236 & 266 & 236 & 254 & 270 \\
\hline & Other vehicle & 100 & 115 & 122 & 116 & 94 & 144 & 111 \\
\hline & Animal ridden & 224 & 249 & 277 & 269 & 240 & 231 & 196 \\
\hline E862 & Poisoning by petroleum products & * & * & 5 & * & - & * & * \\
\hline E863 & Poisoning by agricultural chemicals & 13 & 10 & 17 & 18 & 22 & 20 & 11 \\
\hline E864 & Poisoning by corrosives \& caustics & * & - & * & * & * & - & - \\
\hline E866 & Poisoning by gases and vapours & - & * & * & * & * & 5 & * \\
\hline E890-899 & Fire and flames & 19 & 26 & 29 & 22 & 18 & 21 & 15 \\
\hline E905 & Venomous animals and plants & 17 & 32 & 75 & 43 & 41 & 46 & 50 \\
\hline E906.0 & Dog bite & * & 5 & 10 & 7 & 6 & * & * \\
\hline E906.8 & Injury by other animal & 147 & 130 & 150 & 140 & 137 & 133 & 122 \\
\hline E919.0 & Agricultural machinery & 123 & 120 & 121 & 114 & 129 & 96 & 134 \\
\hline E919.1-9 & Other machinery & 58 & 27 & 43 & 48 & 25 & 43 & 32 \\
\hline E920 & Cutting and piercing & 104 & 96 & 144 & 119 & 102 & 88 & 106 \\
\hline \multirow[t]{2}{*}{ E922 } & Firearms & 10 & 13 & 18 & 18 & 15 & 11 & 10 \\
\hline & TOTAL SUBSET & 1025 & 1030 & 1251 & 1186 & 1069 & 1096 & 1062 \\
\hline Source: & $\begin{array}{l}\text { NSW Inpatients Statistics Collection (HOIST). } \\
{ }^{*} \text { Number less than five. }\end{array}$ & tre & . & 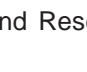 & $h, N$ & 5 & f & \\
\hline
\end{tabular}


injury is a guide to where the work of prevention should be directed, and the information can be used to monitor injury prevention programs. With the updating of the ICD9 to ICD-10, there will be more information about the event of injury available for informing injury prevention.

\section{EMERGENCY DEPARTMENT AND GENERAL PRACTICE SURGERIES}

Another valuable source of information is presentations to emergency departments and to surgeries of general practitioners (GPs) for the treatment of injury. Again, there are large numbers of farm injuries each year that present to these services, but often the information recorded does not identify those injuries that are farm-related. Currently in NSW, there is no statewide system for collecting emergency department presentations or GP presentations. However, a number of hospitals over the last decade have started to collect injury information from their emergency departments using the Emergency Department Information System (EDIS) system. , $7,8^{-1}$

A study of farm injuries presenting to the Tamworth Base Hospital found that during the 15 month study period there were 422 people who sustained an injury on farms, three-quarters were males and 40 per cent were aged 24 years or less. ${ }^{9}$ The majority were Australian ( 97.4 per cent) who lived in the study area (94.3 per cent). Of the people who presented to the emergency department only 28.5 per cent were then admitted to hospital, the majority were discharged (68.9 per cent). Of those killed, just over half (55.1 per cent) were working for an income. The most common agents involved in the injurious event were horses and motorcycles.

In NSW there has not been a study examining injuries that present to the surgeries of GPs; however, a study in Queensland collected injury presentation information from both emergency departments and surgeries of GPs. ${ }^{10}$ The study found that similar injuries present to both places, with a slight tendency for the more serious injuries of fracture and concussion to present directly to an emergency department.

Information collected from emergency departments and the surgeries of GPs is useful for prioritising work at the local community level, directing where further research needs to be undertaken, monitoring programs, and for allocating resources.

\section{WHERE DOES THIS INFORMATION LEAD US?}

Analysis of injury and fatality data suggests that in NSW we need to do further work to reduce fatal injuries as a result of tractor rollovers, vehicle accidents, drowning in dams (especially for children less than five years of age), felling trees, and injuries in those working in the cereal grains, sheep, meat cattle, and pig industries. To reduce injuries that lead to hospitalisation, we need to be working on prevention efforts in the areas of animal-related injuries, in particular horse riding; motorcycle injuries; agricultural machinery; and farm vehicles. Emergency department information suggests that we need to do further work with injury involving horses and motorcycles, injuries to children, and work-related injuries.

Some of the work specified above is already underway. A major program of training is happening through the Managing Farm Safety Course. The course is aimed at farm managers and owners, to help them develop the knowledge and practical skills to manage the risks of injury and illness associated with life and work on farms, and thereby increase their productivity. Farmsafe NSW is working with Farmsafe Australia and individual agricultural industries to develop resources aimed at providing specific information in the Managing Farm Safety Course for particular commodity groups.

In May 2000, WorkCover NSW allocated \$2.4 million for a program that provides a $\$ 200$ rebate per tractor for farmers to fit a Roll Over Protective Structure; this campaign is described elsewhere in this issue of the Bulletin. Farmsafe NSW is heavily involved in both the NSW Water Safety Taskforce and the Farmsafe Australia Child Safety on Farms strategy, which is trying to reduce the number of children who drown in dams. NSW Agriculture and TAFE have developed a 'Tractor Operation and Maintenance' Course for all people who use tractors. The Australian Centre for Agricultural Health and Safety is currently developing resources for vehicle safety on the farm.

The NSW Department of Health and Farmsafe NSW have developed a health promotion package called the 'Safer farm environments project', which is a scheme that provides resources and offers mini-grants for farm safety interventions for rural area health services. ${ }^{11}$ Farmsafe NSW and WorkCover NSW have developed a Future Farmers resource package that provides material and guidance to run a field day to introduce Year 9 and 10 agricultural students to hazards on farms and safe work practices. $^{12}$

There is an increasing awareness of the need for training programs for drivers of All Terrain Vehicles (ATV or 4wheeled motorcycles) and 2-wheel motorcycles; many manufacturers are now examining the possibilities for providing suitable training before purchase or at the point of sale. Resources promoting safe horse riding and handling have been developed and distributed to pony clubs and other interested groups. ${ }^{13}$ 


\section{WHAT ELSE SHOULD WE BE DOING?}

The effectiveness of the interventions that are currently being undertaken will need to be studied, including costbenefit analyses. More work needs to be done to develop resources aimed at adolescent males who ride motorcycles and adolescent females who ride horses. Further work needs to be undertaken in addressing the issue of vehicle safety on farms. Further resources and infrastructure for local farm safety action groups need to be identified and implemented. Continued promotion of the Managing Farm Safety Course is required, in order to provide skills to farmers to effectively manage their occupational health and safety risk.

\section{REFERENCES}

1 Coleman R, Fragar L. The Farm Injury Optimal Dataset. Farm Injury Surveillance. Coding Guidelines. Moree, NSW: Australian Centre for Agricultural Health and Safety, 1996.

2 Fragar L, Franklin R, Coleman R. The Farm Injury Optimal Dataset. Version 1.2 Moree, NSW: Australian Centre for Agricultural Health and Safety and the Rural Industries Research Development Corporation, 2000.

3 National Occupation Health and Safety Commission. Workrelated traumatic fatalities in Australia, 1989-1992. Sydney: National Occupational Health and Safety Commission, 1998.

4 Franklin R, Mitchell R, Driscoll T, Fragar L. Farm-Related Fatalities in Australia, 1989-1992. Moree, NSW: Australian Centre for Agricultural Health and Safety, National Occupational Health and Safety Commission, and the Rural Industries Research Development Corporation, 2000.
5 Fragar LJ, Franklin RC. The Health and Safety of Australia's Farming Community. Moree, NSW: Australian Centre for Agricultural Health and Safety and the Rural Industries Research Development Corporation, 2000.

6 Wolfenden K. Non-fatal rural injury: A study in coastal and inland areas of the New England Region, Australia. Newcastle, NSW: PhD Thesis, University of Newcastle, 1992.

7 Clarke L, Payne D. Farm injury profile North West Plains. Moree, NSW: Australian Agricultural Health Unit, 1992.

8 Coleman R, Weatherspoon D. Farm Injury Presentation to Barwon District Emergency Departments in 1994. Moree, NSW: Australian Agricultural Health Unit, 1995.

9 Davies J, Franklin R. Farm injuries presenting to Tamworth Base Hospital Emergency Department, 1997-98 (unpublished).

10 Franklin R, Chater AB, Fragar L, Ferguson K. Rural Injury in Central Queensland: Injury data from eleven Emergency Departments and nine General Practice surgeries, 1995 1996. Moree, NSW: Australian Centre for Agricultural Health and Safety and the Rural Industries Research Development Corporation, 2000.

11 Farmsafe NSW. Reducing Farm Injury in NSW-Health Promotion for Safer Farm Environments Moree, NSW: Farmsafe NSW, 2000.

12 Farmsafe NSW. Future Farmers: A Rural Health and Safety Resources for High School Students. Moree, NSW: Farmsafe NSW, 2001

13 Pilgrim C. Horse Play No Helmet, No Boots, NO WAY!: Safety Education Program for Children. Gloucester, NSW: Gloucester Community Health, 1994. 